\title{
Treatment of acquired drug resistance in multiple myeloma by combination therapy with XPO1 and topoisomerase II inhibitors
}

Joel G. Turner ${ }^{1}$, Jana L. Dawson ${ }^{1}$, Steven Grant ${ }^{2}$, Kenneth H. Shain ${ }^{1,3}$, William S. Dalton ${ }^{3,4}$, Yun Dai ${ }^{2}$, Mark Meads ${ }^{1}$, Rachid Baz ${ }^{1,3}$, Michael Kauffman ${ }^{5}$, Sharon Shacham ${ }^{5}$ and Daniel M. Sullivan ${ }^{1,6,7^{*}}$

\begin{abstract}
Background: Acquired drug resistance is the greatest obstacle to the successful treatment of multiple myeloma (MM). Despite recent advanced treatment options such as liposomal formulations, proteasome inhibitors, immunomodulatory drugs, myeloma-targeted antibodies, and histone deacetylase inhibitors, MM is still considered an incurable disease.

Methods: We investigated whether the clinical exportin 1 (XPO1) inhibitor selinexor (KPT-330), when combined with pegylated liposomal doxorubicin (PLD) or doxorubicin hydrochloride, could overcome acquired drug resistance in multidrug-resistant human MM xenograft tumors, four different multidrug-resistant MM cell lines, or ex vivo MM biopsies from relapsed/refractory patients. Mechanistic studies were performed to assess co-localization of topoisomerase II alpha (TOP2A), DNA damage, and siRNA knockdown of drug targets.

Results: Selinexor was found to restore sensitivity of multidrug-resistant 8226B25, 8226Dox6, 8226Dox40, and U266PSR human MM cells to doxorubicin to levels found in parental myeloma cell lines. NOD/SCID-y mice challenged with drug-resistant or parental U266 human MM and treated with selinexor/PLD had significantly decreased tumor growth and increased survival with minimal toxicity. Selinexor/doxorubicin treatment selectively induced apoptosis in CD138/light-chain-positive MM cells without affecting non-myeloma cells in ex vivo-treated bone marrow aspirates from newly diagnosed or relapsed/refractory MM patients. Selinexor inhibited XPO1-TOP2A protein complexes (proximity ligation assay), preventing nuclear export of TOP2A in both parental and multidrugresistant MM cell lines. Selinexor/doxorubicin treatment significantly increased DNA damage (comet assay/Y-H2AX) in both parental and drug-resistant MM cells. TOP2A knockdown reversed both the anti-tumor effect and significantly reduced DNA damage induced by selinexor/doxorubicin treatment.
\end{abstract}

Conclusions: The combination of an XPO1 inhibitor and liposomal doxorubicin was highly effective against acquired drug resistance in in vitro MM models, in in vivo xenograft studies, and in ex vivo samples obtained from patients with relapsed/refractory myeloma. This drug combination synergistically induced TOP2A-mediated DNA damage and subsequent apoptosis. In addition, based on our preclinical data, we have initiated a phase I/II study with the XPO1 inhibitor selinexor and PLD (ClinicalTrials.gov NCT02186834). Initial results from both preclinical and clinical trials have shown significant promise for this drug combination for the treatment of MM.

Keywords: Acquired drug resistance, Liposomal doxorubicin, Multiple myeloma, Mouse models, Relapsed/refractory myeloma, XPO1 inhibition

(Continued on next page)

\footnotetext{
* Correspondence: Dan.Sullivan@moffitt.org

${ }^{1}$ Chemical Biology and Molecular Medicine Program, H. Lee Moffitt Cancer

Center \& Research Institute, Tampa, FL, USA

${ }^{6}$ Department of Blood and Marrow Transplantation, H. Lee Moffitt Cancer

Center \& Research Institute, Tampa, FL, USA

Full list of author information is available at the end of the article
} 
(Continued from previous page)

Abbreviations: DAPI, 4',6-Diamidino-2-phenylindole; MM, Multiple myeloma; PLD, Pegylated liposomal doxorubicin; TOP2A, Topoisomerase II alpha; XPO1, Exportin 1

\section{Background}

In cancer cells, the location of a tumor-suppressive or oncogenic protein within the cell is as important as its expression. We have shown that cancer cells utilize the process of nuclear-cytoplasmic transport through the nuclear pore complex to effectively evade anti-cancer mechanisms [1-5]. In our previous studies, we have shown that knockdown of exportin 1 (XPO1) protein by siRNA or inhibition with an XPO1 inhibitor will sensitize drug-resistant myeloma cells to the topoisomerase II (TOP2) inhibitor doxorubicin $[3,5]$. We have also shown that XPO1 inhibitors are able to prevent nuclear export and promote nuclear accumulation of the tumor suppressor protein p53, and prevent the export of the drug target TOP2A $[3,5]$. In addition, XPO1 inhibitors were found to reverse de novo drug-resistance of multiple myeloma (MM) cells in high-density cell culture models and drug resistance conferred to MM cell lines when co-cultured with bone marrow stromal cells [5].

Recent publications have indicated that XPO1 inhibitors, particularly the orally available clinical compound selinexor (KPT-330), may be effective against various malignancies, including breast cancer [6, 7], glioblastoma [8], hepatocellular carcinoma [9], kidney cancer [10, 11], leukemia [12-16], lung cancer [17], mantle cell lymphoma $[18,19]$, melanoma [20, 21], mesothelioma [22], nonHodgkin lymphoma [23], ovarian cancer [7], pancreatic cancer $[24,25]$, prostate cancer $[25,26]$, and MM $[5,13,27]$.

Recent studies in MM have shown that XPO1 protein levels are increased in plasma cells from newly diagnosed MM patients when compared with normal plasma cells [13, 27] or with plasma cells from those with monoclonal gammopathy of undetermined significance and smoldering MM [27]. In addition, high levels of XPO1 may be associated with decreases in event-free and overall survival in MM [13]. When treated with XPO1 inhibitors, 21 different human MM cell lines were found to have decreased cell viability $[3,5,13,27]$. XPO1 inhibitors in MM have been shown to dysregulate the following cancer-related proteins or mRNAs: c-myc, CDC25A, BRD4, p53, Mcl-1, BCl-xL, NF-kB, p21, p27, IkB, FOXO3A, FOXO1A, PP2A, PUMA, BAX, CHOP, C10orf10, MIC1, IL-6, VEGF, MIP1ß, and IL-10 [5, 13, 27].

What has not been addressed in previous studies is whether XPO1 inhibitors are effective in overcoming acquired drug-resistant MM phenotypes, which develop in patients during treatment with standard of care therapies. In patients with $\mathrm{MM}$, acquired drug resistance is a major obstacle, as the disease is considered incurable despite significant advances afforded by immunomodulatory drugs (thalidomide, lenalidomide, pomalidomide), proteasome inhibitors (bortezomib, carfilzomib, ixazomib), antibodies targeting SLAMF7 protein (elotuzumab) and CD-38 (daratumumab), histone deacetylase inhibitors (panobinostat), and high-dose chemotherapy with autologous stem cell rescue.

The recent resurgence of doxorubicin as a treatment for multiple myeloma has been observed in the clinic due to its reformulation in poly(ethylene glycol)-coated liposomes. This formulation increases circulation time and has a unique toxicity profile, including mild myelosuppression, minimal alopecia, and no cardiac toxicity. In addition, liposomal doxorubicin accumulates preferentially in tissues with increased microvascular permeability seen in cancers [28-30]. In the present study, we show that XPO1 inhibition sensitized drug-resistant MM cells to liposomal doxorubicin in in vitro and in vivo models and ex vivo in relapsed/refractory patient MM cells, thus demonstrating that this combination may provide the means for overcoming acquired drug resistance in MM.

\section{Methods \\ Cell lines}

Human MM cell lines RPMI 8226, U266, and NCI-H929 were obtained from the American Type Culture Collection (ATCC; Manassas, VA). MM cell lines 8226B25 and U266PSR were developed incrementally [31, 32]. The U266PSR cell line expresses a modest increase in Mcl-1 [33] and markedly lower expression of the apoptosispromoting factor Bim [31, 32], resulting in enhanced cell survival by inhibiting apoptosis. Doxorubicin-resistant 8226Dox6 and 8226Dox40 cell lines were produced by the incremental addition of doxorubicin [34]; these cell lines were found to overexpress the MDR1 gene, which prevented intracellular accumulation of doxorubicin, resulting in resistance $[35,36]$. All cell lines were authenticated by the Moffitt Cancer Center Molecular Genomics Core Facility according to ATCC guidelines [37].

\section{Drug-resistant cell lines treated with XPO1 inhibitors and doxorubicin}

Parental 8226 and U226 and drug-resistant 8226B25, 8226Dox6, 8226Dox40, and U266PSR human MM cells were grown at low-density (log growth phase) conditions $\left(3-4 \times 10^{5}\right.$ cells $\left./ \mathrm{mL}\right)$ and cultured for $20 \mathrm{~h}$ with either $300 \mathrm{nM}$ selinexor (Karyopharm Therapeutics) or $10 \mathrm{nM}$ 
KOS-2464 (Bristol-Myers Squibb) with and without $2 \mu \mathrm{M}$ doxorubicin (Sigma Chemical). Optimal drug concentrations were determined by titration experiments. Cells were fixed in Cytofix/Cytoperm buffer (BectonDickinson) and permeabilized in Perm/Wash buffer (Becton-Dickinson), and apoptosis was measured by flow cytometry using anti-activated caspase 3/Alexa Fluor 488 (Cell Signaling Technology) staining.

\section{Bone marrow aspirate processing and apoptosis assay of patient myeloma cells}

Bone marrow aspirates were collected from newly diagnosed $(n=19)$ and relapsed $(n=12) /$ refractory $(n=10)$ patients. Isolated bone marrow mononuclear cells were incubated at $4-8 \times 10^{6} / \mathrm{mL}$ in $200 \mu \mathrm{L}$ RPMI (Fisher) containing $10 \%$ FBS in 96-well plates, treated with either selinexor $(300 \mathrm{nM})$ or KOS-2464 (300 nM) with and without $2 \mu \mathrm{M}$ doxorubicin, and incubated for $20 \mathrm{~h}$ in a $5 \% \mathrm{CO}_{2}$ humidified incubator. The cells were then fixed and assayed for apoptosis according to methods outlined in Turner et al. [5].

\section{NOD/SCID- $\gamma$ mouse studies with selinexor \pm PLD}

Drug-resistant U266PSR human myeloma cells $\left(10^{6}\right)$ or parental U266 cells $\left(5 \times 10^{6}\right)$ were injected subcutaneously into flanks of female NOD/SCID- $\gamma$ mice, and tumors were allowed to grow for 14 days before the start of treatment [31]. Mice were treated with PLD $(0.5 \mathrm{mg} / \mathrm{kg})$ once weekly by intraperitoneal injection, by oral gavage with selinexor $(10 \mathrm{mg} / \mathrm{kg}$ ) twice weekly, or with the combination where selinexor treatment was followed 1-2 h later by PLD injection. Five mice were used per experimental group. Tumors were measured by calipers, and tumor volumes $\left(\mathrm{mm}^{3}\right)$ were calculated by the formula (length $\times$ width $\left.^{2}\right) / 2$. Animals were killed upon achieving a tumor volume $>2000 \mathrm{~mm}^{3}$ or if the mouse lost $>15 \%$ of its body weight; this was used to define survival. Drug toxicity was assayed by mouse weights with a decrease of $\geq 10 \%$ considered an indication of toxicity by the drug regimen.

\section{Proximity ligation assay}

Log-phase H929, 8226, 8226B25, 8226Dox6, U226, and U226PSR MM cells were placed at plateau conditions $\left(4 \times 10^{6}\right.$ cells $\left./ \mathrm{mL}\right)$ and treated with $300 \mathrm{nM}$ selinexor for 4 h. Cells were washed with PBS, and cytospins were made at $1 \times 10^{5}$ cells/slide and fixed with $4 \%$ paraformaldehyde/PBS and permeabilized with $0.5 \%$ Triton X100. Slides were blocked in $2 \%$ BSA/PBS and incubated with primary antibodies to TOP2A (Kis1; Millipore) and XPO1 (H-300; Santa Cruz). Proximity ligation assay was performed according to the manufacturer's protocol (Olink Bioscience, Uppsala, Sweden) [38]. A red fluorescent signal was generated only when XPO1 and TOP2A were in close proximity $(<40 \mathrm{~nm})$. 4',6-Diamidino-2- phenylindole (DAPI) was used to stain the nuclei. Samples were observed with a Leica TCS SP5 AOBS laser scanning confocal microscope. The total number of foci per nucleus and cell were analyzed for number and area. This experiment was repeated three times. Western blots were made of the selinexor-treated cells at $4 \mathrm{~h}$ for XPO1 and TOP2A protein expression levels.

\section{Neutral comet assay}

Drug-resistant 8226B25, 8226Dox6, and U266PSR and parental 8226 and U226 cells grown under log-phase conditions were placed at high-density conditions (2$4 \times 10^{6}$ cells $\left./ \mathrm{mL}\right)$, and selinexor $(100 \mathrm{nM})$ was added to media for $20 \mathrm{~h}$ followed by the addition of $5 \mu \mathrm{M}$ doxorubicin for $1 \mathrm{~h}$. Neutral comet assay to determine DNA damage was performed according to the manufacturer's protocol (Trevigen, Gaithersburg, MD) [39, 40]. Proteinase $\mathrm{K}$ was added to digest any protein-associated DNA damage caused by topoisomerase-mediated formation of cleavable complexes, indicating that DNA damage was due to double-strand breaks produced from TOP2 [41]. Electrophoresis was performed at room temperature in TBE buffer at a constant $0.85 \mathrm{~V} / \mathrm{cm}$ for $15 \mathrm{~min}$. Slides were rinsed very briefly with $\mathrm{dd}_{2} \mathrm{O}$ and then fixed in $70 \%$ ethanol for $5 \mathrm{~min}$. Slides were air-dried and then stored at room temperature in a slide box containing desiccant until comets were stained and viewed by microscopy. Comets were stained with SYBR green (Molecular Probes) diluted at 1:10,000 in TBE. Images were taken with $\times 40$ objective lens using a fluorescein filter. The Loats Associates Incorporated Comet Analysis System was used to calculate tail moment [42], which is the product of distance and normalized intensity integrated over the tail length. This is a damage measurement combining the amount of DNA in the tail with the distance of migration (severity of damage). A minimum of 50 comets were analyzed for each dose, and each experiment was repeated three times.

\section{Gamma-H2AX and TOP2A knockdown}

Cells were treated with single-agent doxorubicin $(2 \mu \mathrm{M})$, selinexor (300 nM), and their combination for $20 \mathrm{~h}$ and then assayed for phospho-H2AX (Ser139) expression (JBW301, FITC conjugate, Millipore) by flow cytometry $(n=4)$. To determine if apoptosis and DNA strand breaks are dependent on the presence of TOP2A, H929 MM cells were transfected by electroporation with a TOP2A-specific siRNA (Silencer Select Validated cat. \#4390824, Ambion). Electroporation of MM cells was accomplished by a method outlined in Turner et al. [3]. A control group of cells was transfected with a non-coding siRNA. Transfected (TOP2A knockdown and control siRNA) H929 MM cells were then incubated with selinexor (300 nM) +/doxorubicin $(2 \mu \mathrm{M})$ for $20 \mathrm{~h}$ and assayed by flow cytometry 
for DNA double-strand breaks using phospho-H2AX (Ser139) expression (JBW301) and apoptosis by activatedcaspase 3 (ASP175, AF488, Cell Signaling).

\section{Results}

XPO1 inhibition sensitizes drug-resistant MM cell lines to doxorubicin

Apoptosis results (flow cytometry using activated caspase 3) in human drug-resistant and parental MM cells after 20-h concurrent treatment with selinexor $(300 \mathrm{nM})$ or KOS-2464 $(10 \mathrm{nM}) \pm$ doxorubicin $(2 \mu \mathrm{M})$ are shown in Fig. 1. Both U266 and 8226 parental cell lines were highly sensitive to single-drug treatment with doxorubicin. Drugresistant 8226B25 (Fig. 1a) and U266PSR MM cell lines (Fig. 1b) and doxorubicin-resistant 8226Dox6 (Fig. 1c) and 8266Dox40 MM cell lines (Fig. 1d) were resistant to single-agent doxorubicin (5.9-, 11.6-, 16.7-, and 10.7-fold, respectively) compared with parental cells. The XPO1

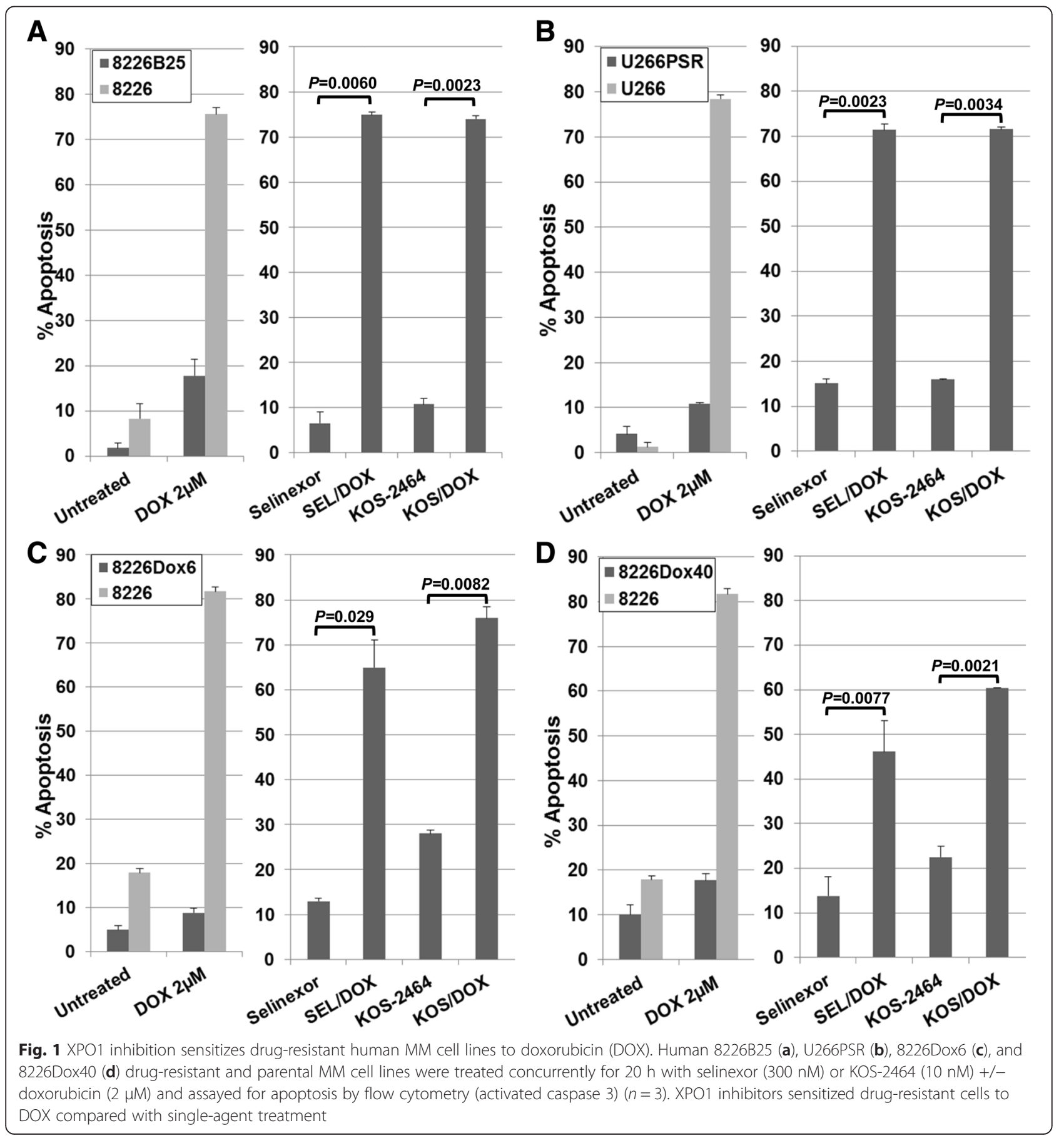


inhibitor selinexor sensitized drug-resistant human MM 8226B25 $(P=0.0060)$, U266PSR $(P=0.0023)$, 8226Dox6 $(P=0.029)$, and $8226 \operatorname{Dox} 40(P=0.0077)$ cell lines to doxorubicin compared with single-agent treatment with doxorubicin alone. In addition, KOS-2464 also sensitized drug-resistant human MM 8226B25 $(P=0.0023)$, U266PSR $(P=0.0034), 8226$ Dox6 $(P=0.0 .029)$, and 8226Dox40 $(P=0.0077)$ cell lines to doxorubicin compared with single-agent treatment with doxorubicin alone (Fig. 1a-d).

Ex vivo treatment of newly diagnosed, relapsed/refractory patient MM cells with KOS-2464 and selinexor sensitizes cells to doxorubicin

CD138 ${ }^{+} /$light chain ${ }^{+} \mathrm{MM}$ cells were isolated from bone marrow aspirates from newly diagnosed $(n=19)$ and relapsed $(n=12)$ or refractory $(n=10)$ patients. The relapsed/refractory patients had received therapies that included an average of 4.7 regimens of chemotherapy, including two or more of the following drugs or drug combinations: busulfan, carfilzomib, cytoxan, dexamethasone, elutozumab, pegylated liposomal doxorubicin (PLD or Doxil), panobinostat, pomalidomide, prednisone, revlimid (lenalidomide), velcade (bortezomib), and melphalan with autologous stem cell transplantation.

Both newly diagnosed and relapsed/refractory MM patient cells were sensitized by selinexor $\left(P=8.0 \times 10^{-11}\right.$ and $P=1.37 \times 10^{-8}$, respectively $)$ and KOS-2464 $\left(P=9.9 \times 10^{-11}\right.$ and $P=7.3 \times 10^{-9}$, respectively) to doxorubicin (Fig. 2a, c) as shown by activated caspase 3 staining and detection by flow cytometry. In contrast, CD138/light-chain doublenegative non-myeloma cells from the same patient bone marrow aspirates were not sensitized to apoptosis by XPO1 inhibitors (Fig. 2b, d).

In vivo NOD/SCID- $\gamma$ mouse studies with selinexor and PLD In mouse studies, drug-resistant U266PSR human MM cells and parental U266 cells controls were used. U266PSR
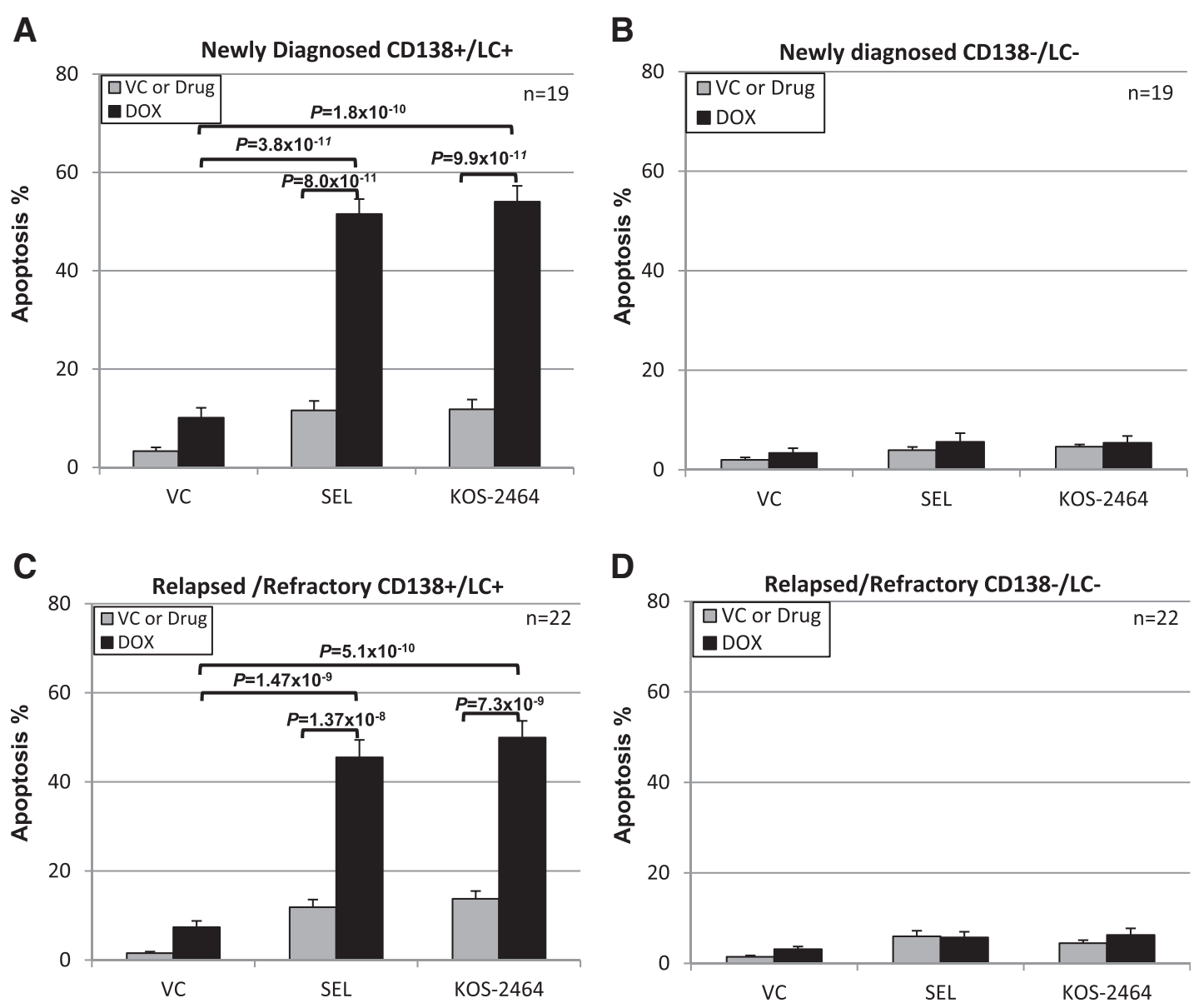

Fig. 2 Selinexor and KOS-2464 sensitize newly diagnosed and relapsed patient MM cells to doxorubicin. Bone marrow mononuclear cells were isolated and treated with selinexor or KOS-2464 +/- doxorubicin and fluorescently labeled with antibodies against activated caspase 3, CD138, and light chain (kappa or lambda). Newly diagnosed $(n=19)$ and relapsed $(n=22)$ CD-138/light-chain double-positive MM patient samples were all sensitized by selinexor and KOS-2464 to doxorubicin $\left(P \leq 1.37 \times 10^{-8}\right)$ versus single-agent treatment as shown by increased apoptosis (a, $\left.\mathbf{c}\right)$. Non-myeloma CD138/light-chain double-negative patient cells were not sensitized to apoptosis by XPO1 inhibitors (b, d) 
cells have been shown to be approximately seven- to eightfold more resistant to doxorubicin than U226 parental cells (Fig. 1b) [31-33]. As shown in Fig. 3b, PLD combined with selinexor reduced parental U266 tumor growth versus single-agent PLD $(P=0.0003)$ or selinexor $(P=0.0079)$. PLD combined with selinexor also reduced drug-resistant U266PSR tumor growth (Fig. 3a) versus single-agent PLD $(P=0.001)$ or selinexor $(P=0.009)$. Selinexor/PLD significantly improved survival in U266-challenged mice when compared with single-agent selinexor $(P=0.0002)$ or PLD $(P=0.0024)$ (Fig. 3d) and in U266PSR when compared with selinexor $(P=0.0095)$ or PLD $(P=0.0018)$ (Fig. 3c). At the end of the study (4 months), $40 \%$ of the U266PSR-challenged mice and $60 \%$ of the U266 parental MM-challenged mice had survived; all untreated control, single-agent PLD-treated, and selinexortreated mice were euthanatized due to tumor size $\left(>2000 \mathrm{~mm}^{3}\right)$ before the end of the study. Toxicity, assessed by weight loss greater than $10 \%$, was less than $2 \%$ in all treatment groups.

\section{Selinexor inhibits XPO1-TOP2A binding}

To determine whether selinexor specifically inhibits XPO1-TOP2A binding, proximity ligation assays were performed on parental 8226, H929, and U266 MM cell lines and drug-resistant 8226B25, 8226Dox6, and U226PSR cell lines (Fig. 4). Selinexor blocked proximity co-localization of XPO1 and TOP2A as shown by the number of XPO1-TOP2A foci (Fig. 4a). Selinexor significantly decreased the number of foci in the nucleus and whole cells (Fig. 4b) in H929 $(P \leq 0.004)$, U266 $(P \leq 0.001)$, U266PSR $(P \leq 0.033), 8226(P \leq 0.0004)$, 8226Dox6 $(P \leq 0.005)$, and 8226B25 $(P \leq 0.046)$ cells. XPO1 and TOP2A protein levels were unaffected by selinexor treatment for up to 4-6 h (Fig. 4a, inset). Selinexor covalent modification of the XPO1 binding site precluded
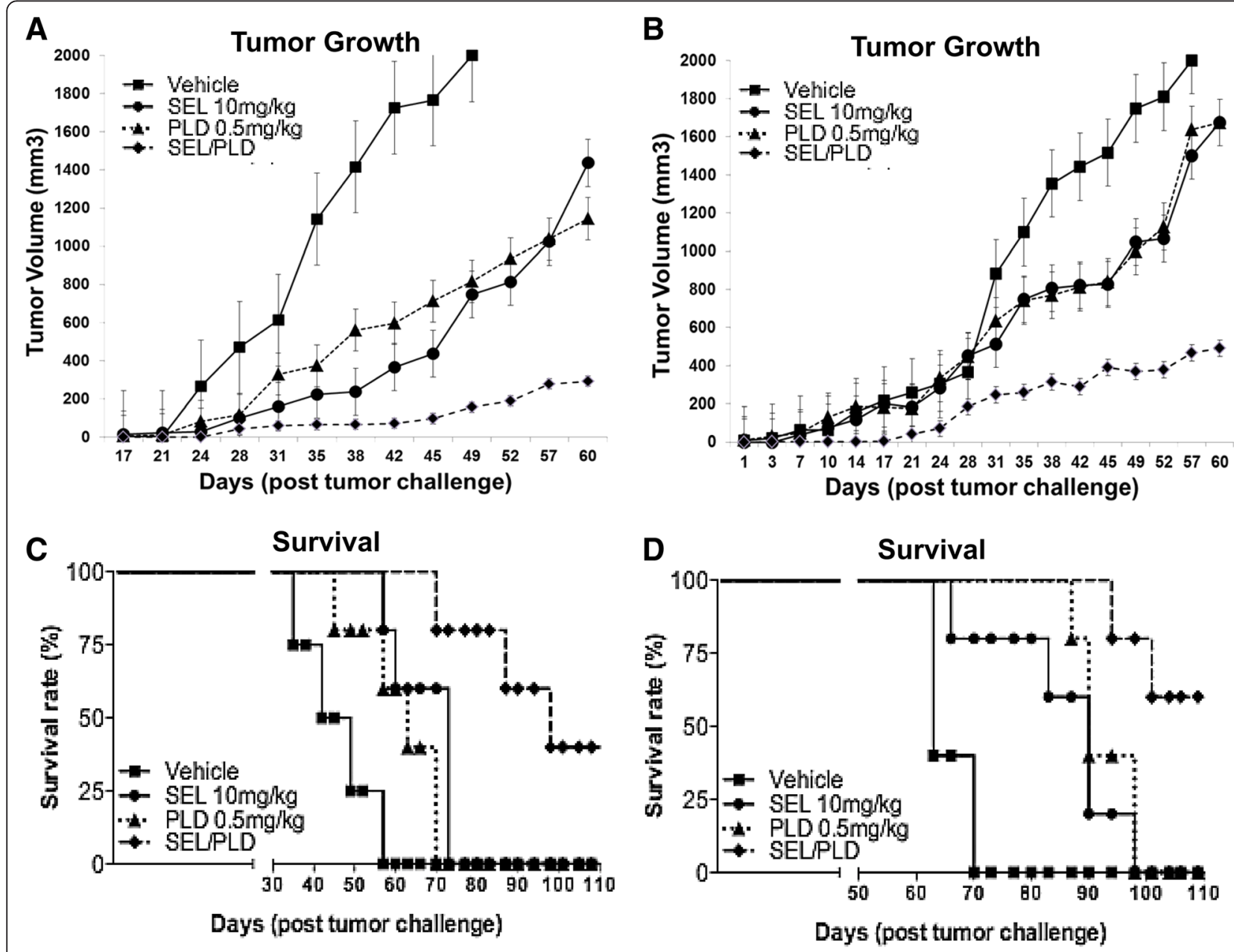

Fig. 3 In vivo studies. PLD/selinexor treatment reduced drug-resistant U266PSR (a) and parental U266 (b) tumor growth compared with singleagent treatment with PLD $(P=0.001)$ or selinexor $(P=0.009)$ in drug-resistant U266PSR $(\mathbf{a})$ and PLD $(P=0.0003)$ or selinexor $(P=0.0079)$ in parental U266 (b). c, d: Selinexor/PLD significantly improved survival in U266PSR-challenged mice compared with single-agent selinexor $(P=0.0095)$ or PLD $(P=0.0018)(\mathbf{c})$ and in U266 compared with selinexor $(P=0.0002)$ or PLD $(P=0.0024)(\mathbf{d})$ 

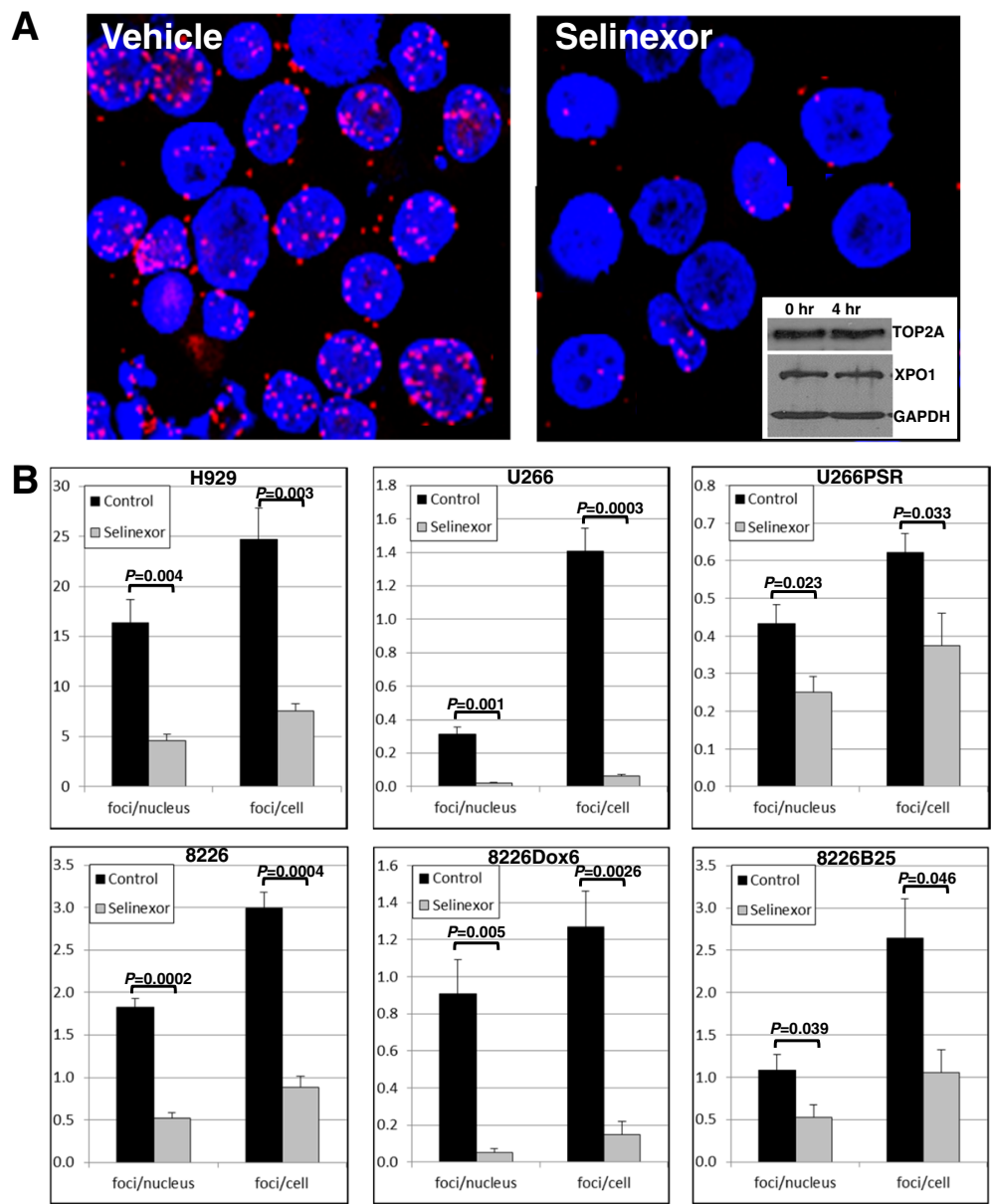

Fig. 4 Selinexor inhibits XPO1-TOP2A binding. Parental H929, U266, and 8226 and drug-resistant U266PSR, 8226Dox6, and 8226 B25 plateau-density human MM cells $\left(3 \times 10^{6} / \mathrm{ml}\right)$ were treated with selinexor $(300 \mathrm{nM})$, cytospun, and assayed for intracellular co-localization of XPO1 and TOP2A by proximity ligation assay. A red fluorescent signal was generated only when XPO1 and TOP2A were in close proximity $(<40 \mathrm{~nm})$. a Selinexor blocked proximity co-localization of XPO1 and TOP2A. Inset, selinexor treatment did not affect XPO1 or TOP2A protein levels at $4 \mathrm{~h}$ as shown by Western blot. $\mathbf{b}$ Analysis of the number of XPO1-TOP2A foci showed that selinexor significantly decreased the number of foci in the nucleus and whole cells of both parental and drug-resistant MM cells

XPO1 binding the nuclear export signal of TOP2A, thus preventing the nuclear export of TOP2A and increasing the amount of nuclear enzyme.

\section{XPO1 inhibitors increased DNA damage when used with doxorubicin}

Human $8226 \mathrm{MM}$ cells $\left(2 \times 10^{6} / \mathrm{mL}\right)$ were treated with selinexor $(100 \mathrm{nM})$ for $20 \mathrm{~h}$ followed by doxorubicin $(5 \mu \mathrm{M})$ for an additional $1 \mathrm{~h}$, and DNA fragmentation was measured by the neutral comet assay (Fig. 5). Selinexor/doxorubicin treatment increased DNA damage over single-agent doxorubicin or selinexor in U266 $\left(P=3.2 \times 10^{-6}\right.$ ) $\left.P=2.5 \times 10^{-5}\right)$, PSR $\left(P=9.9 \times 10^{-9} / P=6.7 \times 10^{-12}\right), 8226$ $\left(P=2.4 \times 10^{-10} / P=3.8 \times 10^{-11}\right), 8226$ Dox6 $\left(P=3.1 \times 10^{-9} /\right.$ $\left.P=4.6 \times 10^{-8}\right)$, and B25 $\left(P=3.4 \times 10^{-17} / P=4.7 \times 10^{-21}\right)$
MM cell lines $(n=50$ comets each per cell line and treatment condition for three experiments each) (Fig. 5).

\section{DNA damage and apoptosis induced by selinexor/ doxorubicin is TOP2A dependent}

DNA damage was measured by phospho-H2AX expression in selinexor- and doxorubicin-treated cells. 8226, 8226B25, 8226Dox6, U266, and U266PSR human MM cells were treated concurrently for $20 \mathrm{~h}$ and stained for phospho-H2AX expression by flow cytometry (Fig. 6). DNA damage was synergistically induced by the combination of selinexor and doxorubicin compared with single-agent doxorubicin or selinexor in parental 8226 $(P \leq 0.024)$ and U266 $(P \leq 0.013) \mathrm{MM}$ cell lines and in drug-resistant 8226B25 $(P \leq 0.015)$, 8226Dox6 $(P \leq 0.0027)$, and U266PSR $(P \leq 0.027)$ MM cell lines (Fig. 6a). Phospho- 

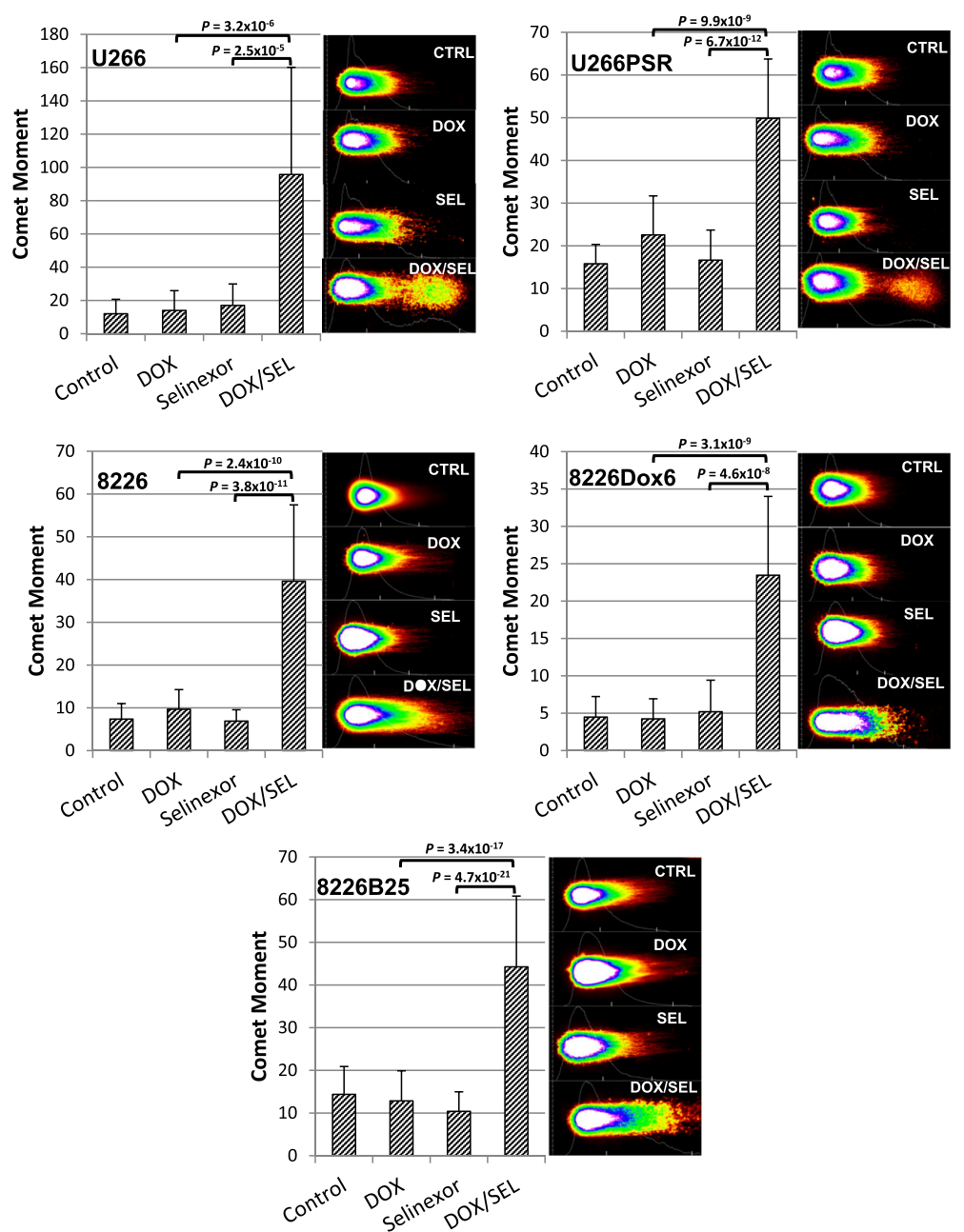

Fig. 5 Comet DNA fragmentation assay. High-density human 8226 and U226 and drug-resistant cell lines 8226Dox6, 8226B25, and U266PSR MM $\left(2 \times 10^{6} / \mathrm{mL}\right)$ were treated with selinexor $(100 \mathrm{nM})$ followed by doxorubicin $(5 \mu \mathrm{M})$. DNA fragmentation (double-strand breaks) was measured by the neutral comet assay. Doxorubicin or selinexor, when used as single agents, increased DNA double-strand cleavage compared with untreated controls. However, selinexor + doxorubicin further increased DNA fragmentation over doxorubicin or selinexor alone

H2AX levels increased four- to sixfold in selinexor- and doxorubicin-treated cells compared with selinexor or doxorubicin alone. When cells were transfected with a TOP2A-specific siRNA, phospho-H2AX levels decreased significantly $(P=0.0006)$ (Fig. 6b). Apoptosis was also significantly reduced in selinexor- and doxorubicin-treated cells with TOP2A knockdown (Fig. 6b). These data indicate that DNA damage and subsequent cell death induced by selinexor/doxorubicin synergy is TOP2A dependent.

\section{Discussion}

Drug resistance is the greatest obstacle for treatment of MM and many other cancers. In this study, we demonstrated the possibility that acquired drug resistance in MM may be overcome by a combinatorial therapy including the XPO1 inhibitor selinexor with the TOP2 inhibitor doxorubicin. The drug-resistant cell lines used in this study included human MM made resistant to doxorubicin (8226Dox6 and 8226Dox40) and cells made resistant to the proteasome inhibitor bortezomib (8266B25 and U266PSR); however, all of these cell lines have a multidrug-resistant phenotype. The mechanism of drug resistance of 8224Dox6 and 8226Dox40 MM cell lines has been shown to be due to an upregulation of the MDR-1 gene [34-36]. These cells have been shown to be resistant to many chemotherapeutic agents, including doxorubicin, daunorubicin, mitoxantrone, acronycine, etoposide, melphalan, and vincristine. Drug-resistant 8226B25 and U266PSR MM cell lines were developed by the incremental addition of bortezomib to 8226 and U266 parental cell lines. These cells were found to be highly resistant to bortezomib, carfilzomib, doxorubicin, and melphalan and therefore also have a multidrugresistant phenotype (data not shown). The U266PSR cell 

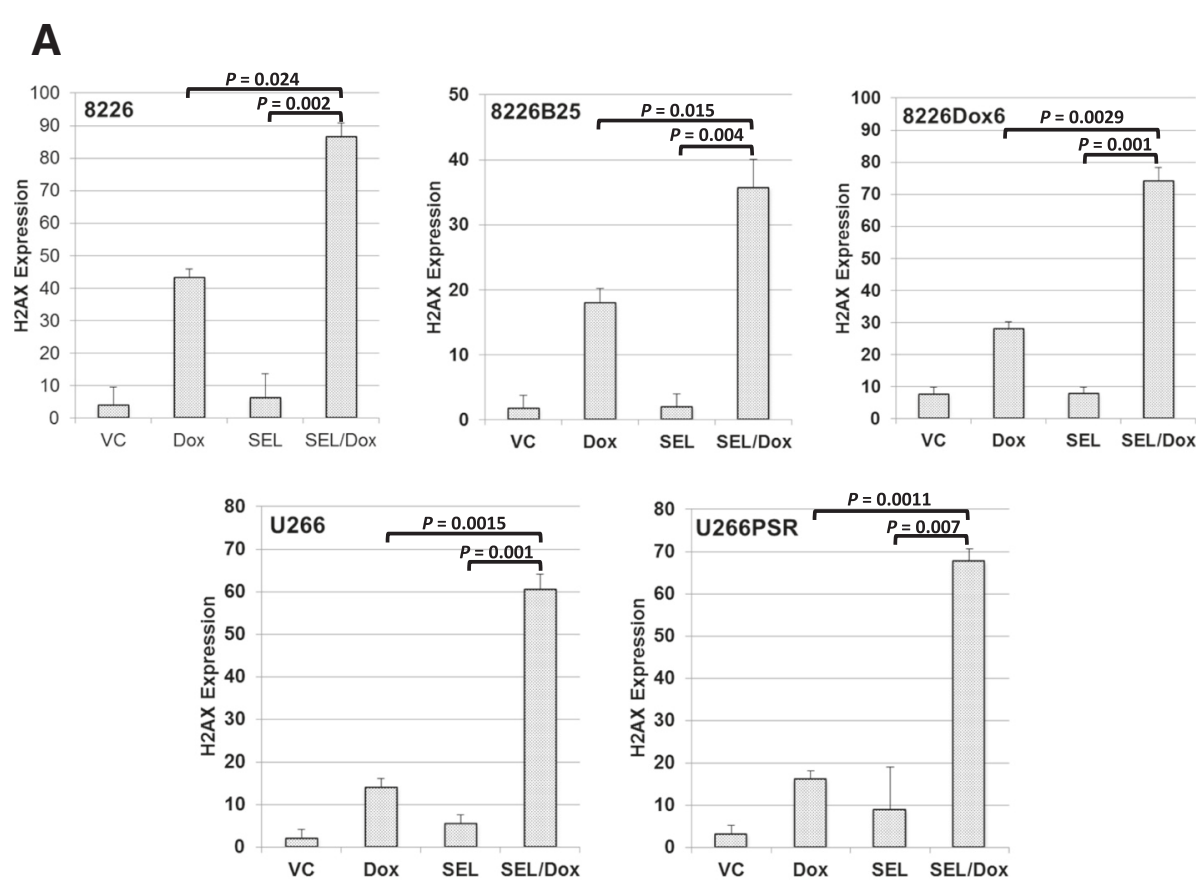

\section{B}
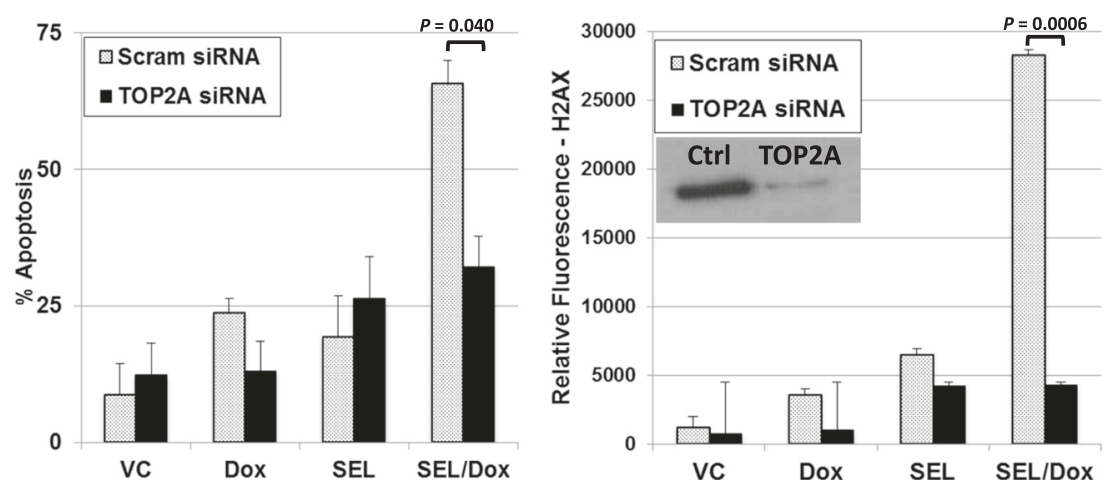

Fig. 6 Mechanism for selinexor and doxorubicin synergy. a Parental MM cell lines 8226 and U226 and drug-resistant 8226B25, 8226Dox6, and U266PSR cells were treated with doxorubicin $(2 \mu \mathrm{M})$, selinexor (300 nM), or the combination for $20 \mathrm{~h}$. Both parental and drug-resistant cell lines, when treated with the combination of selinexor and doxorubicin, had significantly increased DNA damage as shown by increased phospho-H2AX (Ser139) expression $(n=4)$. b SiRNA knockdown of TOP2A resulted in a substantial decrease in DNA damage (phospho-H2AX (Ser139)) and apoptosis, suggesting that selinexor and doxorubicin induced DNA damage, and subsequent apoptosis is TOP2A dependent. Inset, TOP2A knockdown (Western blot)

line expresses a modest increase in Mcl-1 [33] and markedly lower expression of the apoptosis-promoting factor Bim [31, 32], resulting in enhanced cell survival by inhibiting apoptosis and resulting in multidrug resistance.

The TOP2 poison, doxorubicin, functions by arresting TOP2A in cleavable complexes, resulting in doublestrand DNA breaks and subsequent apoptotic cell death of cancer cells [43-45]. Doxorubicin has seen resurgence in the clinic because of the development of new liposomal formulations [28]. Pegylated liposomal doxorubicin provides reduced toxicity, increases in vivo circulation time, and accumulates preferentially in tumors, resulting in increased efficacy in the treatment of MM [28-30].
We demonstrated by proximity ligation assay that TOP2A and XPO1 co-localization is disrupted when MM cells are incubated with selinexor. These data correlate well with previous studies where de novo MM drug resistance to doxorubicin is caused by nuclear export of TOP2A, an effect that is reversed by blocking nuclear export of TOP2A with an XPO1 inhibitor [3, 5, 40, 46]. XPO1 inhibitors such as selinexor prevent export of TOP2A, keeping it in the nucleus and in close proximity to the DNA. We found that, when XPO1 inhibitors are used with doxorubicin or PLD, DNA damage is increased (comet assay/phospho-H2AX), resulting in apoptosis and improving the effectiveness of 
doxorubicin. In this study, we demonstrated that this twodrug combination is also highly effective against drugresistant myeloma, in both cell lines and cells derived from patients. siRNA knockdown of TOP2A significantly decreased both DNA damage and apoptosis, confirming this mechanism of action. The synergistic effect seen with selinexor combined with doxorubicin also translated to drugresistant MM cell lines (in vitro and in vivo) and in MM cells isolated from relapsed/refractory patient bone marrow. Relapsed/refractory patients received multiple rounds of chemotherapy that included an average of 4.7 lines of chemotherapy. These patient cells, like the drug-resistant cell lines, are also highly drug-resistant; however, the combination of selinexor and doxorubicin was effective in the ex vivo treatment of these cells.

Based on these pre-clinical data, we have initiated a phase I/II clinical trial with selinexor and PLD in relapsed/refractory multiple myeloma patients. Preliminary results of the study have been presented at the annual meeting of the American Society of Clinical Oncology; and while the dose escalation continues, encouraging evidence of preliminary efficacy is noted among the 11 response evaluable patients who are heavily pretreated (median of 6 prior lines of therapy) [47]. Specifically two patients had a very good partial response, two patients had a partial response, and another two patients had a minimal response.

\section{Conclusions}

Selinexor, an orally active selective inhibitor of XPO1mediated nuclear export, is currently undergoing phase 1 and phase 2 studies in a variety of indications, including combinations with PLD and carfilzomib, in both relapsed and refractory MM patients. The results presented in our study support combinatorial clinical trials in relapsed and refractory $\mathrm{MM}$, and perhaps other cancers, that utilize TOP2A therapies.

\section{Acknowledgements}

We thank Rasa Hamilton (Moffitt Cancer Center) for editorial assistance. Our study also received valuable assistance from Jodi Kroeger in the Flow

Cytometry Core, and from the Microscopy Core, and Tissue Core Facilities at the Moffitt Cancer Center, an NCl-designated Comprehensive Cancer Center, supported under NIH Grant P30-CA76292.

\footnotetext{
Funding

The H. Lee Moffitt Cancer Center \& Research Institute is supported in part by $\mathrm{NCl}$ Cancer Center Support Grant P30 CA076292. Additional support was provided by the Bankhead-Coley Team Science Project 2BT03-43424 grant and NIH CA194051 grant, the V Foundation and the Moffitt Cancer Center Foundation. Work done at Virginia Commonwealth University was supported by NIH grants P50-CA142509 and CA167708 and the Leukemia and Lymphoma Society of America 6472-15.
}

Availability of data and materials

Not applicable. All data used for conclusions are presented in the manuscript and figures.

\section{Authors' contributions}

JGT designed the experiments, performed the mouse studies, in vitro and ex vivo drug studies, $\mathrm{H} 2 \mathrm{AX}$ assays, statistical analyses and wrote the manuscript. JLD carried out the comet assays and proximity ligation assays. $S G, Y D, K H S, M M$, and WSD provided drug-resistant cell lines and input for the experimental design. $\mathrm{RB}$ is currently performing the ongoing clinical trial. DMS directed the research project and co-wrote the manuscript. All authors read and approved the final manuscript.

\section{Competing interests}

The author and co-authors from the Moffitt Cancer Center and Virginia Commonwealth University declare that they have no competing interests. Co-authors from Karyopharm Therapeutics (Michael Kauffman and Sharon Shacham) provided the XPO1 inhibitor selinexor.

\section{Consent for publication}

Not applicable.

\section{Ethics approval and consent to participate}

For human sample acquisition, written informed consent approved by an Institutional Review Board was obtained from all patients, in accordance with the Declaration of Helsinki. Patient samples were de-identified and obtained through the Institutional Review Board-approved Total Cancer Care ${ }^{\oplus}$ protocol at the Moffitt Cancer Center.

All mouse studies were reviewed and approved by the Institutional Animal Care and Use Committee (IACUC), Research Integrity \& Compliance - Research \& Innovation at the University of South Florida.

\section{Author details}

${ }^{1}$ Chemical Biology and Molecular Medicine Program, H. Lee Moffitt Cancer Center \& Research Institute, Tampa, FL, USA. ${ }^{2}$ Massey Cancer Center, Virginia Commonwealth University, Richmond, VA, USA. ${ }^{3}$ Department of Malignant Hematology, H. Lee Moffitt Cancer Center \& Research Institute, Tampa, FL, USA. ${ }^{4}$ M2Gen ${ }^{\otimes}$ Biotechnologies, H. Lee Moffitt Cancer Center \& Research Institute, Tampa, FL, USA. ${ }^{5}$ Karyopharm Therapeutics, Natick, MA, USA. ${ }^{6}$ Department of Blood and Marrow Transplantation, H. Lee Moffitt Cancer Center \& Research Institute, Tampa, FL, USA. ${ }^{7} \mathrm{H}$. Lee Moffitt Cancer Center \& Research Institute, 12902 Magnolia Drive, Tampa, FL 33612, USA.

Received: 7 July 2016 Accepted: 18 August 2016

Published online: 24 August 2016

\section{References}

1. Turner JG, Sullivan DM. CRM1-mediated nuclear export of proteins and drug resistance in cancer. Curr Med Chem. 2008;15:2648-55.

2. Turner JG, Dawson J, Sullivan DM. Nuclear export of proteins and drug resistance in cancer. Biochem Pharmacol. 2012;83:1021-32.

3. Turner JG, Marchion DC, Dawson JL, Emmons MF, Hazlehurst LA, Washausen P, Sullivan DM. Human multiple myeloma cells are sensitized to topoisomerase II inhibitors by CRM1 inhibition. Cancer Res. 2009;69:6899-905.

4. Turner JG, Dawson J, Cubitt CL, Baz R, Sullivan DM. Inhibition of CRM1dependent nuclear export sensitizes malignant cells to cytotoxic and targeted agents. Sem Cancer Biol. 2014;27C:62-73.

5. Turner JG, Dawson J, Emmons MF, Cubitt CL, Kauffman M, Shacham S, Hazlehurst LA, Sullivan DM. CRM1 inhibition sensitizes drug resistant human myeloma cells to topoisomerase II and proteasome inhibitors both in vitro and ex vivo. J Cancer. 2013;4:614-25.

6. Cheng Y, Holloway MP, Nguyen K, McCauley D, Landesman Y, Kauffman MG, Shacham S, Altura RA. XPO1 (CRM1) inhibition represses STAT3 activation to drive a survivin-dependent oncogenic switch in triple-negative breast cancer. Mol Cancer Ther. 2014;13:675-86.

7. Miyake T, Pradeep S, Wu SY, Rupaimoole R, Zand B, Wen Y, Gharpure KM, Nagaraja AS, Hu W, Cho MS, et al. XPO1/CRM1 inhibition causes antitumor effects by mitochondrial accumulation of elF5A. Clin Cancer Res. 2015;21:3286-97.

8. Green AL, Ramkissoon SH, McCauley D, Jones K, Perry JA, Hsu JH, Ramkissoon LA, Maire CL, Hubbell-Engler B, Knoff DS, et al. Preclinical antitumor efficacy of selective exportin 1 inhibitors in glioblastoma. Neuro Oncol. 2015;17:697-707. 
9. Zheng Y, Gery S, Sun H, Shacham S, Kauffman M, Koeffler HP. KPT-330 inhibitor of XPO1-mediated nuclear export has anti-proliferative activity in hepatocellular carcinoma. Cancer Chemother Pharmacol. 2014;74:487-95.

10. Inoue H, Kauffman M, Shacham S, Landesman Y, Yang J, Evans CP, Weiss $\mathrm{RH}$. CRM1 blockade by selective inhibitors of nuclear export attenuates kidney cancer growth. J Urol. 2013;189(6):2317-26.

11. Wettersten HI, Landesman Y, Friedlander S, Shacham S, Kauffman M, Weiss $\mathrm{RH}$. Specific inhibition of the nuclear exporter exportin-1 attenuates kidney cancer growth. PLoS One. 2014;9:e113867.

12. Ranganathan P, Yu X, Na C, Santhanam R, Shacham S, Kauffman M, Walker A, Klisovic R, Blum W, Caligiuri M, et al. Preclinical activity of a novel CRM1 inhibitor in acute myeloid leukemia. Blood. 2012;120:1765-73.

13. Tai YT, Landesman Y, Acharya C, Calle Y, Zhong MY, Cea M, Tannenbaum D, Cagnetta A, Reagan M, Munshi AA, et al. CRM1 inhibition induces tumor cell cytotoxicity and impairs osteoclastogenesis in multiple myeloma: molecular mechanisms and therapeutic implications. Leukemia. 2014;28(1):155-65.

14. Lapalombella R, Sun Q, Williams K, Tangeman L, Jha S, Zhong Y, Goettl V, Mahoney E, Berglund C, Gupta S, et al. Selective inhibitors of nuclear export show that CRM1/XPO1 is a target in chronic lymphocytic leukemia. Blood. 2012;120:4621-34.

15. Hing ZA, Mantel R, Beckwith KA, Guinn D, Williams E, Smith LL, Williams K, Johnson AJ, Lehman AM, Byrd JC, et al. Selinexor is effective in acquired resistance to ibrutinib and synergizes with ibrutinib in chronic lymphocytic leukemia. Blood. 2015;125:3128-32.

16. Etchin J, Montero J, Berezovskaya A, Le BT, Kentsis A, Christie AL, Conway AS, Chen WC, Reed C, Mansour MR, et al. Activity of a selective inhibitor of nuclear export, selinexor (KPT-330), against AML-initiating cells engrafted into immunosuppressed NSG mice. Leukemia. 2016;30(1):190-9.

17. Sun H, Hattori N, Chien W, Sun Q, Sudo M, E-Ling GL, Ding L, Lim SL, Shacham S, Kauffman M, et al. KPT-330 has antitumour activity against non-small cell lung cancer. Br J Cancer. 2014;111:281-91.

18. Zhang K, Wang M, Tamayo AT, Shacham S, Kauffman M, Lee J, Zhang L, Ou Z, Li C, Sun L, et al. Novel selective inhibitors of nuclear export CRM1 antagonists for therapy in mantle cell lymphoma. Exp Hemat. 2013:41:67-78. e64.

19. Tabe Y, Kojima K, Yamamoto S, Sekihara K, Matsushita H, Davis RE, Wang Z, Ma W, Ishizawa J, Kazuno S, et al. Ribosomal biogenesis and translational flux inhibition by the selective inhibitor of nuclear export (SINE) XPO1 antagonist KPT-185. PLoS One. 2015;10:e0137210.

20. Salas Fragomeni RA, Chung HW, Landesman Y, Senapedis W, Saint-Martin JR, Tsao H, Flaherty KT, Shacham S, Kauffman M, Cusack JC. CRM1 and BRAF inhibition synergize and induce tumor regression in BRAF-mutant melanoma. Mol Cancer Ther. 2013;12:1171-9.

21. Pathria G, Wagner C, Wagner SN. Inhibition of CRM1-mediated nucleocytoplasmic transport: triggering human melanoma cell apoptosis by perturbing multiple cellular pathways. J Invest Dermatol. 2012;132:2780-90.

22. De Cesare M, Cominetti D, Doldi V, Lopergolo A, Deraco M, Gandellini P, Friedlander S, Landesman Y, Kauffman MG, Shacham S, et al. Anti-tumor activity of selective inhibitors of XPO1/CRM1-mediated nuclear export in diffuse malignant peritoneal mesothelioma: the role of survivin. Oncotarget. 2015;6:13119-32.

23. Azmi AS, Al-Katib A, Aboukameel A, McCauley D, Kauffman M, Shacham S, Mohammad RM. Selective inhibitors of nuclear export for the treatment of non-Hodgkin's lymphomas. Haematologica. 2013;98:1098-106.

24. Azmi AS, Aboukameel A, Bao B, Sarkar FH, Philip PA, Kauffman M, Shacham S, Mohammad RM. Selective inhibitors of nuclear export block pancreatic cancer cell proliferation and reduce tumor growth in mice. Gastroenterology. 2013;144:447-56.

25. Gao J, Azmi AS, Aboukameel A, Kauffman M, Shacham S, Abou-Samra AB, Mohammad RM. Nuclear retention of Fbw7 by specific inhibitors of nuclear export leads to Notch1 degradation in pancreatic cancer. Oncotarget. 2014:5:3444-54

26. Gravina GL, Tortoreto M, Mancini A, Addis A, Di Cesare E, Lenzi A, Landesman Y, McCauley D, Kauffman M, Shacham S, et al. XPO1/CRM1selective inhibitors of nuclear export (SINE) reduce tumor spreading and improve overall survival in preclinical models of prostate cancer (PCa). J Jematol Oncol. 2014;7:46.

27. Schmidt J, Braggio E, Kortuem KM, Egan JB, Zhu YX, Xin CS, Tiedemann RE, Palmer SE, Garbitt VM, McCauley D, et al. Genome-wide studies in multiple myeloma identify XPO1/CRM1 as a critical target validated using the selective nuclear export inhibitor KPT-276. Leukemia. 2013;27:2357-65.
28. Gabizon AA. Pegylated liposomal doxorubicin: metamorphosis of an old drug into a new form of chemotherapy. Cancer Invest. 2001;19:424-36.

29. Orlowski RZ, Nagler A, Sonneveld P, Blade J, Hajek R, Spencer A, San Miguel J, Robak T, Dmoszynska A, Horvath N, et al. Randomized phase III study of pegylated liposomal doxorubicin plus bortezomib compared with bortezomib alone in relapsed or refractory multiple myeloma: combination therapy improves time to progression. J Clin Oncol. 2007;25:3892-901.

30. Baz RC, Shain KH, Hussein MA, Lee JH, Sullivan DM, Oliver EF, Nardelli LA, Nodzon LA, Zhao X, Ochoa-Bayona JL, et al. Phase II study of pegylated liposomal doxorubicin, low-dose dexamethasone, and lenalidomide in patients with newly diagnosed multiple myeloma. Am J Hematol. 2014;89:62-7.

31. Chen S, Dai Y, Pei XY, Myers J, Wang L, Kramer LB, Garnett M, Schwartz DM, Su F, Simmons GL, et al. CDK inhibitors upregulate $\mathrm{BH}$-only proteins to sensitize human myeloma cells to $\mathrm{BH} 3$ mimetic therapies. Cancer Res. 2012;72:4225-37.

32. Chen $S$, Zhang $Y$, Zhou L, Leng $Y$, Lin $H$, Kmieciak M, Pei XY, Jones $R$, Orlowski RZ, Dai Y, Grant S. A Bim-targeting strategy overcomes adaptive bortezomib-resistance in multiple myeloma through a novel link between autophagy and apoptosis. Blood. 2014;124(17):2687-97.

33. Pei XY, Dai Y, Felthousen J, Chen S, Takabatake Y, Zhou L, Youssefian LE, Sanderson MW, Bodie WW, Kramer LB, et al. Circumvention of Mcl-1dependent drug resistance by simultaneous Chk1 and MEK1/2 inhibition in human multiple myeloma cells. PLoS One. 2014;9:e89064

34. Dalton WS, Durie BG, Alberts DS, Gerlach JH, Cress AE. Characterization of a new drug-resistant human myeloma cell line that expresses P-glycoprotein. Cancer Res. 1986:46:5125-30.

35. Bellamy WT, Dorr RT, Dalton WS, Alberts DS. Direct relation of DNA lesions in multidrug-resistant human myeloma cells to intracellular doxorubicin concentration. Cancer Res. 1988:48:6360-4.

36. Dalton WS, Grogan TM, Rybski JA, Scheper RJ, Richter L, Kailey J, Broxterman HJ, Pinedo HM, Salmon SE. Immunohistochemical detection and quantitation of P-glycoprotein in multiple drug-resistant human myeloma cells: association with level of drug resistance and drug accumulation. Blood. 1989;73:747-52.

37. Marx V. Cell-line authentication demystified. Nat Meth. 2014;11:483-8.

38. Soderberg O, Gullberg M, Jarvius M, Ridderstrale K, Leuchowius KJ, Jarvius J, Wester K, Hydbring P, Bahram F, Larsson LG, Landegren U. Direct observation of individual endogenous protein complexes in situ by proximity ligation. Nat Meth. 2006;3:995-1000.

39. Olive PL, Wlodek D, Banath JP. DNA double-strand breaks measured in individual cells subjected to gel electrophoresis. Cancer Res. 1991;51:4671-6.

40. Engel R, Valkov NI, Gump JL, Hazlehurst L, Dalton WS, Sullivan DM. The cytoplasmic trafficking of DNA topoisomerase Ilalpha correlates with etoposide resistance in human myeloma cells. Exp Cell Res. 2004;295:421-31.

41. Olive PL, Banath JP, Durand RE. Detection of etoposide resistance by measuring DNA damage in individual Chinese hamster cells. J Natl Canc Inst. 1990;82:779-83.

42. Olive $\mathrm{PL}$, Banath JP, Durand RE. Heterogeneity in radiation-induced DNA damage and repair in tumor and normal cells measured using the "comet" assay. Radiat Res. 1990;122:86-94.

43. Giles Gl, Sharma RP. Topoisomerase enzymes as therapeutic targets for cancer chemotherapy. Med Chem. 2005;1:383-94.

44. Barcelo F, Martorell J, Gavilanes F, Gonzalez-Ros JM. Equilibrium binding of daunomycin and adriamycin to calf thymus DNA. Temperature and ionic strength dependence of thermodynamic parameters. Biochem Pharmacol. 1988;37:2133-8

45. Tewey KM, Rowe TC, Yang L, Halligan BD, Liu LF. Adriamycin-induced DNA damage mediated by mammalian DNA topoisomerase II. Science. 1984:226:466-8.

46. Valkov NI, Gump JL, Engel R, Sullivan DM. Cell density-dependent VP-16 sensitivity of leukaemic cells is accompanied by the translocation of topoisomerase llalpha from the nucleus to the cytoplasm. Br J Haematol. 2000;108:331-45.

47. Baz RC, Shain KH, Hussein MA, Lee JH, Sullivan DM, Oliver EF, Nardelli LA, Nodzon LA, Zhao X, Ochoa-Bayona JL, et al. Phase I trial of the combination of selinexor, liposomal doxorubicin and dexamethasone for relapsed and refractory multiple myeloma. J Clin Oncol. 2016;34:8013. 